\title{
EcoTILLING for the identification of allelic variation in the powdery mildew resistance genes mlo and Mla of barley
}

Jensen, Nina Mejlhede; Kyjovska, Z.; Backes, Gunter; Burhenne, K.; Rasmussen, Søren K.; Jahoor, Ahmed

\section{Published in:}

Plant Breeding

DOI:

10.1111/j.1439-0523.2006.01226.x

Publication date:

2006

Document version

Publisher's PDF, also known as Version of record

Citation for published version (APA):

Jensen, N. M., Kyjovska, Z., Backes, G., Burhenne, K., Rasmussen, S. K., \& Jahoor, A. (2006). EcoTILLING for the identification of allelic variation in the powdery mildew resistance genes mlo and Mla of barley. Plant Breeding, 125(5), 461-467. https://doi.org/10.1111/j.1439-0523.2006.01226.x 


\section{EcoTILLING for the identification of allelic variation within the powdery mildew resistance genes $\mathrm{mlo}$ and Mla of barley}

Mejlhede, $N .^{1)}$, Kyjovska, Z. ${ }^{2)}$, Backes, G. ${ }^{1)}$, Burhenne, K. ${ }^{3)}$, Rasmussen S. K. ${ }^{1)}$, and Jahoor, A. ${ }^{1)}$

1) Department of Agricultural Sciences, The Royal Veterinary and Agricultural University, Thorvaldsensvej 40, DK-1871 Frederiksberg C, Copenhagen, Denmark

${ }^{2)}$ Present address: Masaryk University, Department of Genetics and Molecular Biology, Faculty of Science, Kotláøska 2, 60000 Brno, Czech Republic

3) Present address: Novozymes A/S, Hallas Alle 1 building AXS.36, DK-4400 Kalundborg, Denmark

Corresponding author:

Jahoor, A.

E-mail:aha@kvl.dk

Phone: +4535283466

Fax: +4535283468

Keywords: Hordeum vulgare, EcoTILLING, barley, powdery mildew resistance, Mla, mlo. 


\section{ABSTRACT}

In this investigation we describe the successful implementation of a CEL I-based mutation detection technique for discovery and detection of DNA polymorphism in the genes mlo and Mla of barley. The technique is called EcoTILLING, which is a high throughput method to detect and discover new point mutations and small insertions/deletions in DNA. We demonstrate that the method not only reveals polymorphism between different alleles, but also can be used as a powerful genetic marker. The genes mlo and Mla are involved in the defence of barley to the fungal pathogen powdery mildew. The powdery mildew resistance gene mlo is a single copy gene, whereas multiple alleles exist at the Mla locus. With EcoTILLING we were able to identify point mutations and deletions in each of the 11 mlo mutants tested. For Mla we tested 25 natural barley variants, and although the identification was complex due to the presence of highly similar paralogs of Mla, we were able to identify most of the recently identified alleles from Hordeum vulgare ssp. spontaneum. This method offers the possibility to combine different mlo alleles with different Mla alleles from wild barley to obtain cultivars with more durable resistance.

\section{INTRODUCTION}

EcoTILLING is a high throughput method to detect and discover new point mutations and small insertions/deletions in DNA (Comai et al. 2004). The method is gel-based and thereby low cost. EcoTILLING is a variant of TILLING. TILLING is a high throughput nontransgenic strategy for providing allelic series of mutations, including knock-outs (McCallum et al. 2000). It permits the identification of mutations in target genes without the implementation of genetically modified organisms that cause public concern in Europe. The method is therefore of great interest in commercial agriculture.

The wild type Mlo gene encodes a protein, which is probably involved in regulating a cell wall repair process. Its malfunction results in excessive papilla growth and a high level of resistance to powdery mildew. A number of mlo mutants have been reported, of these at least 32 are of proven independent mutational origin and most of them have been sequenced. They are assigned resistance gene symbols mlo1 to mlo32 (Jørgensen 1994, Büschges et al. 1997, Piffanelli et al. 2002, Molina-Cano et al. 2003). Of these, most have been induced by chemical mutagens, five have been induced with radiation, and one (mlo11) is naturally occurring in Ethiopian landraces (Piffanelli et al. 2004). The known inactivated mlo alleles are either characterized by a single point mutation or by deletion of a few nucleotides. Currently, the only way to identify alleles in the mlo gene is either by pedigree or by sequencing of the gene.

The Mla locus is of great interest because of the diversity of resistant phenotypes that are conferred by different Mla resistance specificities. These phenotypes can range from near immunity, associated with a rapid hypersensitive response and early growth arrest of the powdery mildew, to a late response allowing the development of some fungal mycelium 
(Boyd et al. 1995). The Mla region contains multiple classes of genes associated with plant defence responses and genetic variants of the Mla locus are found in cultivars worldwide.

At least 20 very effective alleles of the Mla locus have been identified in a wild barley collected in Israel (Jahoor and Fischbeck 1987, Jahoor and Fischbeck 1993, Kintzios et al. 1995). Currently Mla alleles are mostly determined by resistance tests with a set of powdery mildew isolates. However, the isolates collected in Europe do not possess the corresponding virulence genes to detect the alleles of the Mla locus from wild barley. Therefore, isolates sampled from wild barley in Israel have to be employed for this purpose.

In this study we demonstrate that point mutations in the mlo gene and the natural variation at the Mla locus of barley can easily be detected by EcoTILLING.

\section{MATERIALS AND METHODS}

\section{Plant material}

The plant lines used in this work consisted of 11 barley mlo mutant lines, the cultivar 'Ingrid' (Mlo WT) and 25 barley lines including cultivars from Europe, near isogenic lines in Pallas background (Kølster et al. 1986), and derivatives of wild barley containing known Mla alleles (Jahoor and Fischbeck 1987, Jahoor and Fischbeck 1993, Kintzios et al. 1995).

\section{DNA isolation}

One to two leaves of 8 days old seedlings were freeze-dried, ball-milled with two 3-mm steelballs in a ball-mill (Retsch) and plant DNA was isolated in a $2 \mathrm{ml}$ reaction tube according to the CTAB-protocol (Saghai-Maroof et al. 1984).

\section{CEL I purification}

CEL I was purified after a modified protocol from Oleykowski et al. (1998) using an ÄKTAexplorer 10S chromatography system from Amersham Pharmacia Biotech. All steps were performed at $4^{\circ} \mathrm{C}$.

Step 1: Celery stalks (6.3 $\mathrm{kg}$ fresh from the grocery shop) were juiced in a blender and adjusted to give the composition of buffer $\mathrm{A}(0.1 \mathrm{M}$ Tris $\mathrm{pH} 7.7$ containing $0.1 \mathrm{mM}$ PMSF). The crude extract was filtered through a nylon mesh and centrifuged at 10,000 $\mathrm{g}$ for $30 \mathrm{~min}$. The supernatant was gently stirred and solid $\left(\mathrm{NH}_{4}\right)_{2} \mathrm{SO}_{4}$ was slowly added to a final concentration of $25 \%$ saturation. After $1 \mathrm{~h}$, the suspension was centrifuged at 20,000 $\mathrm{g}$ for 60 min. The supernatant was adjusted to $80 \%\left(\mathrm{NH}_{4}\right)_{2} \mathrm{SO}_{4}$ saturation and stirred for one hour before centrifugation at 20,000 $\mathrm{g}$ for $60 \mathrm{~min}$. The pellet was resuspended in $400 \mathrm{ml}$ buffer B (buffer A containing $0.5 \mathrm{M} \mathrm{KCl}$ ) and thoroughly dialyzed against buffer $\mathrm{B}$.

Step 2: Con A Sepharose 4B (60 ml) from Amersham Biosciences was equilibrated in buffer

B. The dialyzed extract was gently stirred for $2 \mathrm{~h}$ with $50 \mathrm{ml}$ Con A resin and then packed in a 2.6 diameter column prepacked with $10 \mathrm{ml}$ Con A resin. The resin was washed in $600 \mathrm{ml}$ 
buffer B before bound CEL I was batch eluted in $250 \mathrm{ml}$ buffer C (buffer B containing $0.01 \%$ Triton X-100 and 0.3 M methyl- $\alpha$-D-mannopyranoside) at a flow rate of $3 \mathrm{ml} / \mathrm{min}$. Eluted protein was dialyzed against buffer D (50 mM Tris $\mathrm{pH} 8.0$ containing $5 \mathrm{mM}$ methyl- $\alpha-\mathrm{D}$ mannopyranoside, $0.01 \%$ Triton X-100 and $25 \mu \mathrm{M}$ PMSF).

Step 3: The enzyme extract was loaded onto a HiPrep 16/10 Q XL column equilibrated in buffer D. The column was washed in $400 \mathrm{ml}$ buffer D before a linear gradient (0-100\% in 400 $\mathrm{ml}$ ) of buffer $\mathrm{E}$ (buffer D containing $0.5 \mathrm{M} \mathrm{KCl}$ ) was applied at a flow rate of $5 \mathrm{ml} / \mathrm{min}$. Fractions of $4 \mathrm{ml}$ were collected and assayed for CEL I activity. The most active CEL I fractions were pooled and dialyzed against buffer $\mathrm{D}$.

Step 4: The extract was loaded onto a Mono Q $(1 \mathrm{ml})$ column equilibrated in buffer $\mathrm{D}$. The column was washed in $20 \mathrm{ml}$ buffer D before a linear gradient $(0-100 \%$ in $50 \mathrm{ml})$ of buffer $\mathrm{E}$ was applied at a flow rate of $1 \mathrm{ml} / \mathrm{min}$. Fractions of $1 \mathrm{ml}$ were collected. The pUC19 RF-I nicking assay described by Yang et al. (2000) was used to quantify CEL I throughout purification.

\section{PCR primers}

Primers and 5' fluorescent-labelled primers were obtained from Applied Biosystems. Fluorescent-labelled primers contained 5'-labelled VIC-dye (green) or 5'-labelled 6-FAM dye (blue). The primer design was based on the published sequences of Mlo (accession no Y14573) and Mla (accession no AY009938) with melting temperatures around $60^{\circ} \mathrm{C}$. The software 'Primer3' (Rozen and Skaletsky 1988) was used in the primer design. Primer mixes for PCR consisted of 4 primers: labelled and unlabelled forward primers together with labelled and unlabelled reverse primers in the ratio 2:3 (labelled: unlabelled), for a final concentration of $0.5 \mu \mathrm{M}$ in the PCR.

\section{PCR amplification}

PCR was performed in $20 \mu \mathrm{l}$ volumes using $20 \mathrm{ng}$ of extracted DNA (from one or several plants), 1x Taq polymerase buffer (Promega), $0.2 \mathrm{mM}$ dNTPs, $2.5 \mathrm{mM} \mathrm{MgCl} 2,0.5 \mu \mathrm{M}$ primer mix and 0.5 unit Taq Polymerase (Promega).

Amplifications were performed on a GeneAmp PCR System 2700 thermal cycler (PE Applied Biosystem) as follows: $95^{\circ} \mathrm{C}$ for $2 \mathrm{~min}$; eight cycles of touchdown PCR $\left(94^{\circ} \mathrm{C}\right.$ for $30 \mathrm{~s}, 68^{\circ} \mathrm{C}$ for $30 \mathrm{~s}$ decrementing $1^{\circ} \mathrm{C}$ per cycle, $72^{\circ} \mathrm{C}$ for $\left.1 \mathrm{~min}\right) ; 45$ cycles of: $\left(94^{\circ} \mathrm{C}\right.$ for $30 \mathrm{~s}, 60^{\circ} \mathrm{C}$ for $30 \mathrm{~s}, 72^{\circ} \mathrm{C}$ for $1 \mathrm{~min}$ ), $72^{\circ} \mathrm{C}$ for $5 \mathrm{~min}$; denaturation at $99^{\circ} \mathrm{C}$ for $10 \mathrm{~min}$; and slow renaturation with 70 cycles of $30 \mathrm{~s}$ at $70^{\circ} \mathrm{C}$ to $49^{\circ} \mathrm{C}$, decrementing $0.3^{\circ} \mathrm{C}$ per cycle. The last steps in the program inactivate the polymerase, denature the DNA strands and slowly reanneal the strands for the heteroduplex formation. Cycling was followed by CEL I digestion, cleanup, gel electrophoresis, and scanning. 
Table 1: PCR primer used for EcoTILLING of $m l o$ and Mla.

\begin{tabular}{ll} 
Name & oligonucleotide sequence (5' 3 $^{\prime}$ ) \\
\hline mloA-F & CGTGTGCGTACCTGGTAGAG \\
mloA-F-VIC & VIC-CGTGTGCGTACCTGGTAGAG \\
mloA-R & CAAGCCAAGACGACAATCAG \\
mloA-R-FAM & 6-FAM-CAAGCCAAGACGACAATCAG \\
mloB-F & CTGATTGTCGTCTTGGCTTG \\
mloB-F-VIC & VIC-CTGATTGTCGTCTTGGCTTG \\
mloB-R & CTGACTCCATACGCCAAACA \\
mloB-R-FAM & 6-FAM-CTGACTCCATACGCCAAACA \\
mloC-F & TGTTTGGCGTATGGAGTCAG \\
mloC-F-VIC & VIC-TGTTTGGCGTATGGAGTCAG \\
mloC-R & AGAAACCGGAGAGGAGAAGG \\
mloC-R-FAM & 6-FAM -AGAAACCGGAGAGGAGAAGG \\
mloD-F & CCTCACCCTCTTCCTTGACA \\
mloD-F-VIC & VIC-CCTCACCCTCTTCCTTGACA \\
mloD-R & CGTCAGAGCAGTTCATCAGC \\
mloD-R-FAM & 6-FAM -CGTCAGAGCAGTTCATCAGC \\
mloE-F & CCACCGATGAACTTGTCAGT \\
mloE-F-VIC & VIC-CCACCGATGAACTTGTCAGT \\
mloE-R & GAGAGGGGTTTTGTTTGTGC \\
mloE-R-FAM & 6-FAM -GAGAGGGGTTTTGTTGTGC \\
Mla1-3F & AGCAGCTCGACAGCCAAGACAA \\
Mla1-3FFAM & 6-FAM -AGCAGCTCGACAGCCAAGACAA \\
Mla1-3R & CCCAACCCTCCAAATCCAACAA \\
Mla1-3RVIC & VIC-CCCAACCCTCCAAATCCAACAA \\
\hline 6-FAM &
\end{tabular}

6-FAM and VIC are 5' end labelled fluorescence dyes.

\section{CEL I digestion}

The assay was carried out as described by Colbert et al. (2001). For digestion of $10 \mu \mathrm{PCR}$ products in 96-well plates, $20 \mu \mathrm{l}$ of a solution containing $10 \mathrm{mM}$ HEPES (pH 7.5), $10 \mathrm{mM}$ $\mathrm{MgSO}_{4}, 0.002 \%$ (w/v) Triton X-100, $0.2 \mu \mathrm{g} \mathrm{ml}^{-1}$ of bovine serum albumin, and 1/300 dilution of CEL I was added, and the plate was incubated at $45^{\circ} \mathrm{C}$ for $60 \mathrm{~min}$. Reactions were stopped by addition of $5 \mu 10.2 \mathrm{M}$ EDTA ( $\mathrm{pH}$ 8) on ice and the mixture pipetted into wells of a Millipore multiscreen system 96 well filtration plate containing Sephadex G-50 fine (Amersham Biosciences). The eluates were mixed with $5 \mu 1$ of formamide loading solution containing ROX-1000 internal lane standard (200 $\mu \mathrm{g} \mathrm{ml}^{-1}$ bromophenol blue and 1/16 dilution of GeneScan-1000 ROX size standard (Applied Biosystems) in deionised formamide). The sample volume was reduced to $5 \mu \mathrm{l}$ by incubation at $85^{\circ} \mathrm{C}$ for 45 minutes and then stored on ice. 
Table 2: Description of mlo-alleles used in this study

\begin{tabular}{|c|c|c|c|c|}
\hline Allele & variety (mutagen) & Mutational event ${ }^{1}$ & $\begin{array}{l}\text { Effect on } M L O \\
\text { protein }\end{array}$ & $\begin{array}{l}\text { Primer } \\
\text { mix }^{2}\end{array}$ \\
\hline mlo1 & Haisa (X-rays) & $\mathrm{T} 484 \rightarrow \mathrm{A}$ & $\operatorname{Trp} 162 \rightarrow \operatorname{Arg}$ & mloB \\
\hline mlo3 & $\begin{array}{l}\text { Malteria Heda } \\
(\gamma \text {-rays })\end{array}$ & $\begin{array}{l}\text { Deletion of two } \\
\text { nucleotides } 1188 \text { - } \\
1189\end{array}$ & $\begin{array}{l}\text { Frameshift } \\
\text { after Phe395 }\end{array}$ & mloE \\
\hline mlo4 & Foma (X-rays) & $\begin{array}{l}\text { Deletion of } 11 \\
\text { nucleotides } 478-488\end{array}$ & $\begin{array}{l}\text { Frameshift } \\
\text { after Trp159 }\end{array}$ & mloB \\
\hline mlo5 & Carlsberg II (EMS) & $\mathrm{G} 3 \rightarrow \mathrm{A}$ & Met $1 \rightarrow$ Ile & mloA \\
\hline mlo7 & Carlsberg II (EMS) & $\mathrm{G} 677 \rightarrow \mathrm{A}$ & Gly226 $\rightarrow$ Asp & mloC \\
\hline mlo8 & Carlsberg II (EMS) & $\mathrm{A} 1 \rightarrow \mathrm{G}$ & Met $1 \rightarrow$ Val & mloA \\
\hline mlo9 & Diamant (EMS) & $\mathrm{C} 28 \rightarrow \mathrm{T}$ & $\operatorname{Arg} 10 \rightarrow \operatorname{Trp}$ & mloA \\
\hline mlo10 & Foma ( $\gamma$-rays $)$ & $\begin{array}{l}\text { Deletion of } 6 \\
\text { nucleotides 543-548 }\end{array}$ & $\begin{array}{l}\text { Missing } \\
\text { Phe182 and } \\
\text { Thr183 }\end{array}$ & mloB \\
\hline mlo12 & $\begin{array}{l}\text { Elgina } \\
\text { (Nitrosomethylurea) }\end{array}$ & $\mathrm{C} 1396 \rightarrow \mathrm{A}$ & Phe $240 \rightarrow$ Leu & mloC \\
\hline mlo13 & Plena (EMS) & $\mathrm{T} 89 \rightarrow \mathrm{A}$ & Val30 $\rightarrow$ Glu & mloA \\
\hline mlo17 & Plena (EMS) & $\mathrm{C} 92 \rightarrow \mathrm{T}$ & Ser31 $\rightarrow$ Phe & mloA \\
\hline
\end{tabular}

${ }^{I}$ Numbers of nucleotides after the translational start site.

${ }^{2}$ Primer mix refers to primers listed in Table 1.

EMS = ethylmethane sulfonate.

References: (Büschges et al. 1997) and (Piffanelli et al. 2002).

\section{Detection of DNA fragments}

The samples were heated for $96^{\circ} \mathrm{C}$ for $3 \mathrm{~min}$, loaded onto a denaturing $36 \mathrm{~cm}$ well-to-read $5 \%$ polyacrylamide gel. We chose to load only 48 samples on a 96-well gel, since the lanes are very close and strong signals in one lane can sometimes be detected in the neighbouring lanes. The gel was run and analyzed on an ABI PRISM 377 DNA Sequencer using GeneScan 3.1 Software (Perkin Elmer). Results can be displayed as a gel image or as an electropherogram that displays the peak profile of each lane of the gel image. 


\section{RESULTS}

\section{Design of primers for $\mathrm{mlo}$}

Selection of primers was based on the Mlo sequence from Hordeum vulgare ssp. vulgare cultivar "Ingrid" which was available through the NCBI GenBank ${ }^{\circledR}$. The Mlo gene consists of 3163 base pairs including a 5'-UTR (224 base pairs), a coding sequence interrupted by 11 introns, and a 3'-UTR (100 base pairs). Figure 1 shows the overall gene structure. The 12 exons vary in length from 41 base pairs to 396 base pairs. In order to cover the whole coding sequence five primer pairs were designed. The sizes of the five corresponding PCR products were 599, 624, 566, 574 and 837 base pairs. Table 2 summarizes the information on mlo mutants used in this study.

Figure 1: The Mlo gene. Exons are shown as boxes, black parts are the coding sequence and white parts are the 5'UTR and 3'UTR, respectively. Introns are shown as thick black

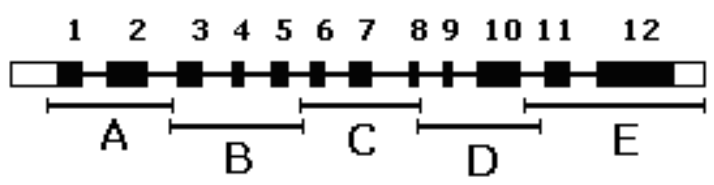
lines. Primer design is illustrated below the gene, where each letter represents the region covered by the respective primer pairs A, B, C, D and E. Sizes of PCR products were 599, $624,566,574$ and 837 base pairs, respectively. Exon numbers are indicated above the gene.

The mlo gene is 3163 base pairs long.

\section{CEL I-based mutation detection of $\mathrm{mlo}$}

We tested DNA from the mutants mlo1, mlo3, mlo4, mlo5, mlo7, mlo8, mlo9, mlo10, mlo12, mlo 13 and mlo17. Mutants mlo5, mlo8, mlo 9 , mlo 13 and mlo17 have single point mutations in exon 1 and we confirmed these point mutations using primer pair A. Mutant mlo 1 has a single point mutation in exon 4, mlo 4 has a 11 base pairs deletion in exon 4 and $m l o 10$ has a 6 base pairs deletion in exon 5 and these three mutants were tested with primer pair B. Mutant mlo7 has a single point mutation in exon 6 and mlo 12 has a single point mutations in exon 7 and these two mutants were tested with primer pair C. Mutant $m l o 3$ has a 2 base pairs deletion in exon 11 and was tested with primer pair E.

As an example, Figure 2 shows a gel image of mutation detection analysis of $m l o 3$ and WT using primer pair E. DNA from Hordeum vulgare ssp. vulgare cultivar "Ingrid" was mixed in a ratio of 1:1 with DNA from mlo3. The PCR and CEL I digestion were carried out as described in material and methods. Mutant mlo3 has a deletion of two nucleotides in the mlo gene compared to WT, and this deletion will result in a heteroduplex formation with a 2 nucleotide DNA loop. The PCR product was then subjected to CEL I endonuclease treatment. CEL I enzyme cuts one of the two DNA strands 3' of a mismatch, which can be a single point mutation or in this case a loop. When the DNA is denatured, the result is fluorescence labelled truncated fragments with either VIC (green), or 6-FAM (blue), which can be detected by an 
ABI automated DNA sequencer. With the primer mix E used for mlo3 and WT, the expected lengths of the truncated fragments are 198 nucleotides VIC (green) and 641 nucleotides 6FAM (blue). Fragments detected by the ABI sequencer were 199 nucleotides VIC (green) and 647 nucleotides 6-FAM (blue) which is in agreement with the expected fragment sizes. The same procedure was repeated for the other mlo mutants.

Figure 2: A gel image of mutation detection analyses on an $\mathrm{ABI}$ automated DNA sequencer running the GeneScan program. The substrate is an 835-837 base pairs heteroduplexed PCR product using DNA from WT and mutant mlo3 and primer mix E, which covers exon 11 and exon 12 of mlo. It is labelled at the $5^{\prime}$ terminal with VIC (green) on one strand and 6-FAM (blue) on the othmer. The substrate was incubated with CEL I enzyme for $60 \mathrm{~min}$. at $45^{\circ} \mathrm{C}$ and then analyzed. In lane 1 the control reaction is shown where PCR is done using DNA from WT only. In lane 2 the reaction is shown when DNA from WT and mlo3 is mixed. Mutant mlo3 contains a 2 nucleotide deletion compared to WT. The blue fragment at approximately 641 nucleotides corresponds to CEL I mismatch-specific cutting on the 6FAM-labelled strand, and the green peak at approximately 198 nucleotides corresponds to the mismatch-specific cutting on the VIClabelled strand. The strong fragments in green and blue in each lane correspond to the full-size uncut PCR fragments of approximately 835-837 nucleotides in length. The sizes of the red standard (ROX1000) are shown on the left.

Table 3: Cel I fragment sizes with labelled primers 6-FAM and VIC observed for the different mlo mutants by EcoTILLING.

\begin{tabular}{lrcccl} 
WT + & \multicolumn{2}{c}{ Expected size $^{\boldsymbol{a}}$} & \multicolumn{2}{c}{ Observed size $^{\boldsymbol{a}}$} & Primer \\
mutant & VIC & 6-FAM & VIC & 6-FAM & mix $^{*}$ \\
\hline mlo1 & 313 & 312 & 315 & 312 & mloB \\
mlo3 & 198 & 641 & 199 & 647 & mloE \\
mlo4 & 317 & 318 & 318 & 319 & mloB \\
mlo5 & 73 & 527 & $73^{\mathrm{b}}$ & 526 & mloA \\
mlo7 & 123 & 444 & 124 & 444 & mloC \\
mlo8 & 71 & 529 & $71^{\mathrm{b}}$ & 528 & mloA \\
mlo9 & 98 & 502 & $99^{\mathrm{b}}$ & 502 & mloA \\
mlo10 & 499 & 131 & 500 & 128 & mloB \\
mlo12 & 282 & 285 & 283 & 285 & mloC \\
mlo13 & 159 & 441 & 160 & 442 & mloA \\
mlo17 & 162 & 438 & 163 & 437 & mloA \\
\hline
\end{tabular}

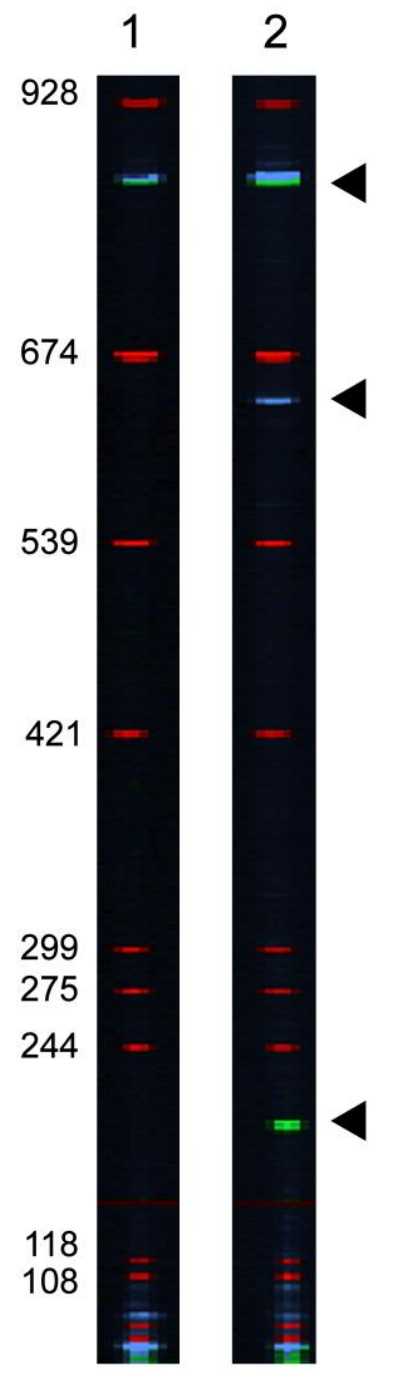

${ }^{a}$ Values are in nucleotides. ${ }^{b}$ We could observe a fragment of this size, but in this area of the gel many fragments are present. *Primer mix refers to primers listed in Table 1. 
In the lower area of the gel, many fragments are abundant. Therefore analysis of the gel in this area is complicated. The noisy signal in the area 0-100 nucleotides is due to the presence of excess fluorescence primers and degraded PCR products with attached fluorescence dyes.

The mlo5, mlos and mlo9 contained mutations close to the primer site; 73, 71 and 98 nucleotides, respectively, and the mutations were therefore confirmed primarily by the presence of the corresponding blue fragment of sizes 526, 528 and 502 nucleotides, respectively. A way to avoid the problem is to locate a primer more distant to the mutation site.

For all of the mlo mutants, the sizes of the fragments generated by EcoTILLING were in agreement with the expected sizes calculated from the sequence information given from the database within a few nucleotides.

\section{Design of primers for Mla}

Selection of primers for the Mla gene was based on an alignment of the coding sequences of Mla1, Mla6, Mla12 and Mla13 from Hordeum vulgare ssp. vulgare available through the NCBI GenBank ${ }^{\circledR}$.

The overall gene structure of Mlal is shown in Figure 3. The gene consists of 4665 base pairs including a $5^{\prime}$-UTR (229 base pairs) interrupted by an intron, a coding sequence (2877 base pairs) interrupted by two introns and a 3'-UTR (234 base pairs).

Figure 3: The Mlal gene. Exons are shown as boxes, black parts are the coding sequence and white parts are the 5'UTR and 3'UTR respectively. Introns are shown as thick black

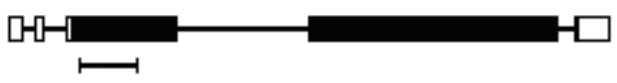
lines. Primer design is illustrated below the gene. The region covered by the primer pair is 451 base pairs. The gene is 4665 base pairs in size.

The coding sequence of Mlal is shown in Figure 4, where shaded nucleotides indicate polymorphic sites for Mla6, Mla12 and Mla13. The 3' end shows a high level of polymorphism between alleles and is not suitable for EcoTILLING. Therefore, we chose the 5 ' end for the primer design as shown in Figure 4. The size of the corresponding PCR product is 451 base pairs. 
Figure 4: Polymorphisms found in the coding sequence of the Mla gene of four near isogenic lines Mla1, Mla6, Mla12 and Mla13. The sequence shown is the coding sequence of Mla1, places where one or more alternative bases are found in the near isogenic lines Mla6, Mla12 and Mla13 are light grey. Mla1-3 forward and reverse primer sites are underlined.

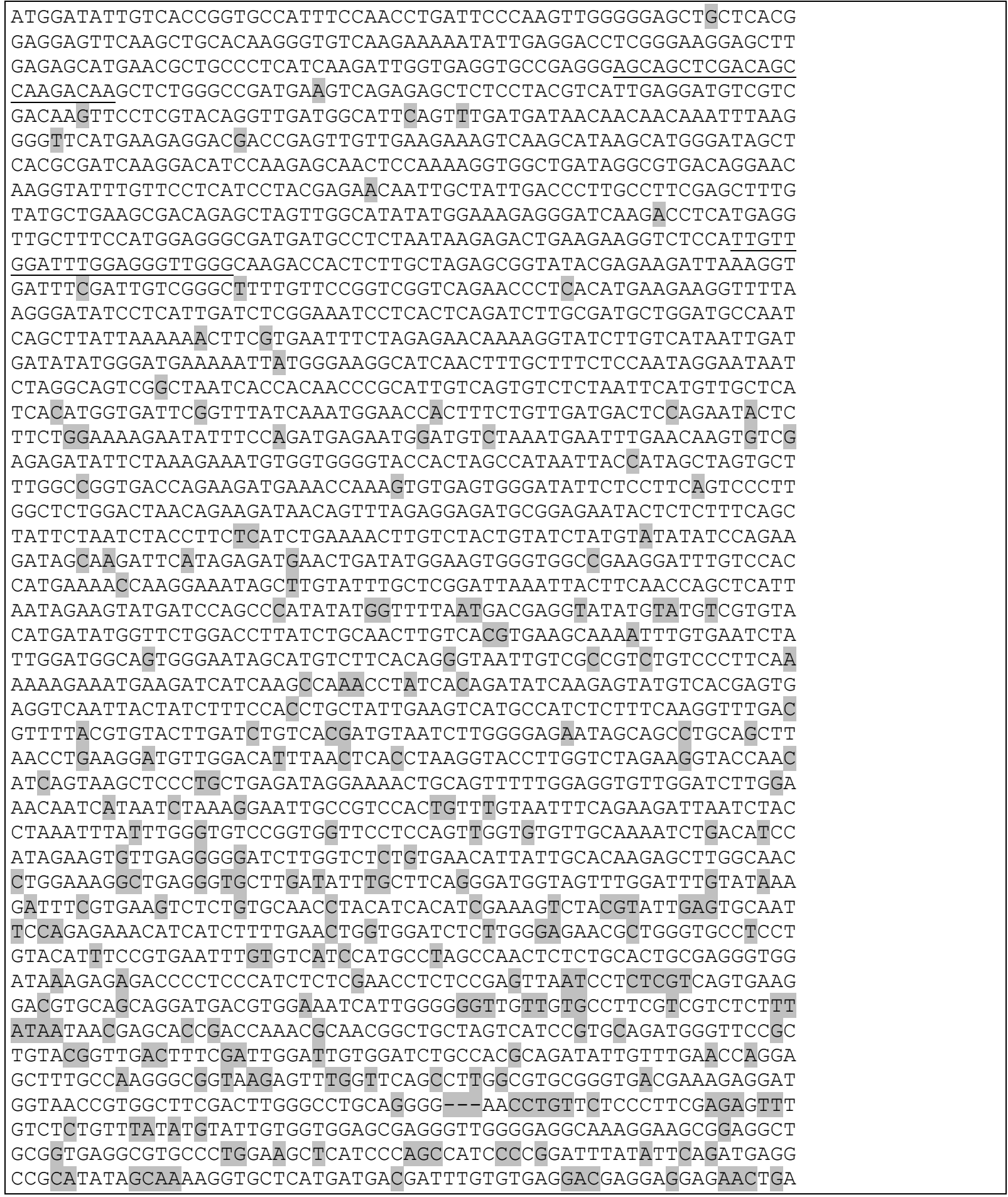




\section{CEL I-based mutation detection for Mla}

In the case of Mla, we observed CEL I digestion products with DNA from a single variety. Normally, we would mix DNA from a standard DNA, which in this case could be Mlal, together with a tester DNA and use the resulting pattern to detect whether the mutant contained allelic differences. However, when the DNA from the variety possessing Mlal was subjected to CEL I-based mutation detection alone, a specific fragment pattern was observed. The same was true for all of the varieties, a specific fragment pattern was observed without mixing the DNA with standard DNA. This indicates that nearly identical copies of the sequence amplified by the primers are present in the respective genomes.

A summary of the observed fragment patterns is shown in Table 4. The fragment pattern detected is rather complex, with multiple mismatches for each of the lines. In the CEL I reaction the enzyme cuts only a small portion of the heteroduplices such that most of the fulllength PCR product is not digested. Therefore, multiple mismatches in the same substrate can be detected. We observed 5-10 point mutations per 451 nucleotides which correspond to 98$99 \%$ identity at the nucleotide level.

Figure 5: Mutation detection analyses of RS20-1 (Mla18). Vertical axis, relative fluorescence units; horizontal axis, fragment length in nucleotides. The upper panel shows the fragments of the 6-FAM-labelled strand, the lower panel shows the fragments of the VIC-labelled strand. Fragments of sizes 78, 105, 216, 230, 282, 289, 295, 346 in the upper panel correspond to the fragments 374, 347, 237, 222, 171, 163 and 157 and 105 respectively. Fragment 429 in the upper panel did not have a detectable counterpart in the lower panel, since it fell into the noisy region below 88 nucleotides. In both panels the full length PCR product of 452 nucleotides is observed.

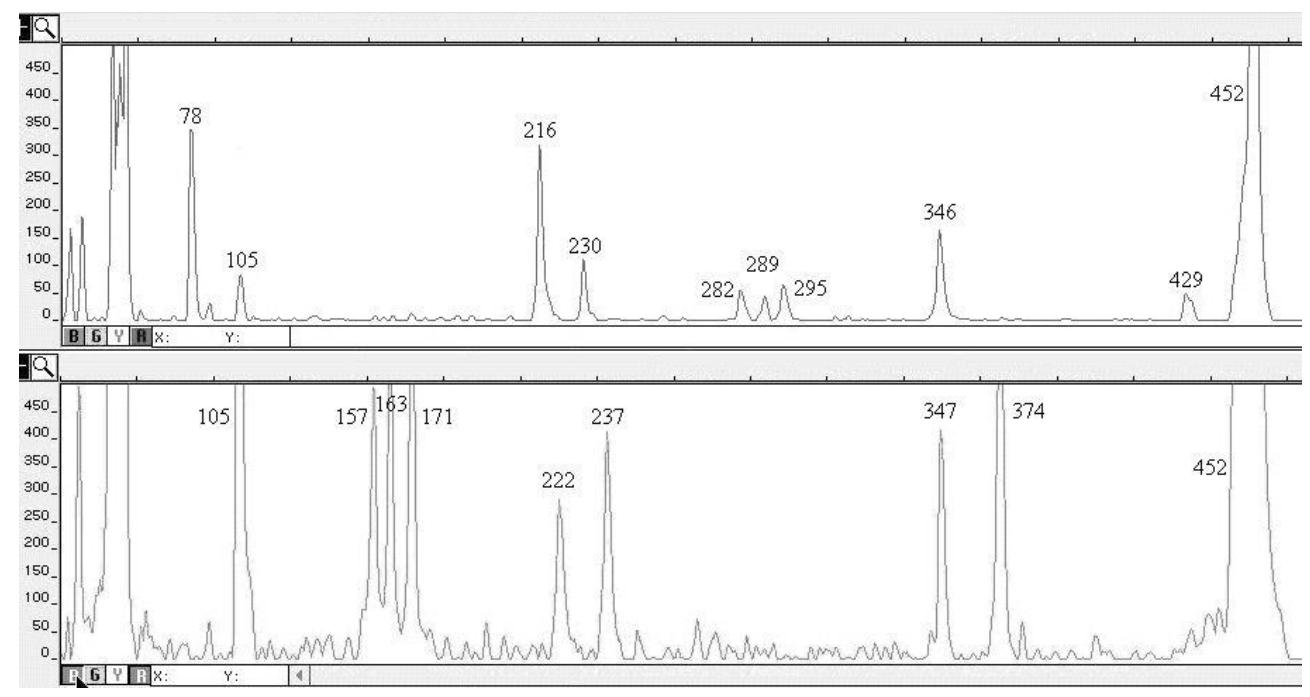

As an example, Figure 5 shows the electropherogram of the mutation detection analysis of line RS20-1 with the powdery mildew resistance gene Mla18. With the forward primer we observed fragments 78, 105, 216, 230, 282, 289, 295 and 346 nucleotides, which correspond to the fragments observed with the reverse primer of $374,347,237,222,171,163,157$ and 
105 nucleotides, respectively. In Table 4, we have omitted fragments below approximately 90 nucleotides, since these fell into the 'noisy' region of the gel.

Table 4: EcoTILLING fragments observed for the different Mla variants

\begin{tabular}{|c|c|c|c|c|c|c|c|c|c|c|c|c|c|c|c|c|c|}
\hline \multirow[b]{2}{*}{ Grp } & \multirow[b]{2}{*}{ Lines } & \multirow[b]{2}{*}{ Gene(s) } & \multirow[b]{2}{*}{ Donor } & \multicolumn{14}{|c|}{ Fragment sizes (labelled 6-FAM / VIC) } \\
\hline & & & & $\frac{f}{m}$ & $\frac{m}{\stackrel{m}{g}}$ & $\frac{\Delta}{\stackrel{D}{\infty}}$ & $\frac{8}{\infty}$ & $\frac{\infty}{N}$ & $\frac{\hat{N}}{\stackrel{n}{\sim}}$ & 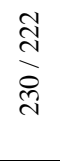 & 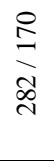 & 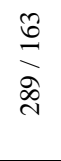 & $\frac{n}{n}$ & 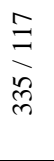 & 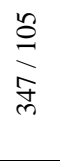 & 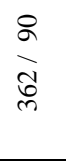 & \\
\hline \multirow{8}{*}{1} & P04B & Mla7 & Lyallpur 3645 & $\Delta$ & & & $\Delta$ & & & $\Delta$ & $\Delta$ & $\boldsymbol{\Delta}$ & & & $\boldsymbol{\Delta}$ & & $\Delta$ \\
\hline & P05 & Mla7 & Lyallpur 3645 & $\boldsymbol{\Delta}$ & & & $\Delta$ & & & $\Delta$ & $\Delta$ & $\Delta$ & & & $\Delta$ & & $\Delta$ \\
\hline & $\mathrm{P} 04 \mathrm{~A}$ & Mla7, Ml-k & Lyallpur 3645 & $\boldsymbol{\Delta}$ & & & $\Delta$ & & & $\boldsymbol{\Delta}$ & $\Delta$ & $\Delta$ & & & $\boldsymbol{\Delta}$ & & $\boldsymbol{\Delta}$ \\
\hline & $\mathrm{P} 07$ & Mla9, Ml-k & Lyallpur 3645 & $\boldsymbol{\Delta}$ & & & $\Delta$ & & & $\Delta$ & $\Delta$ & $\Delta$ & & & $\boldsymbol{\Delta}$ & & $\Delta$ \\
\hline & P09 & Mla10 & Iso 12 (Durani C.I. 6316) & $\boldsymbol{\Delta}$ & & & $\Delta$ & & & $\Delta$ & $\Delta$ & $\boldsymbol{\Delta}$ & & & $\Delta$ & & $\Delta$ \\
\hline & P10 & Mla12 & Emir (C.I. 11790) & $\boldsymbol{\Delta}$ & & & $\Delta$ & & & $\Delta$ & $\boldsymbol{\Delta}$ & $\Delta$ & & & $\Delta$ & & $\Delta$ \\
\hline & OPTIC & Mla12 & Emir (C.I. 11790) & $\boldsymbol{\Delta}$ & & & $\Delta$ & & & $\Delta$ & $\Delta$ & $\Delta$ & & & $\Delta$ & & $\Delta$ \\
\hline & P11 & Mla13 & Rupee (C.I. 4355) & $\boldsymbol{\Delta}$ & & & $\Delta$ & & & $\Delta$ & $\Delta$ & $\Delta$ & & & $\Delta$ & & $\boldsymbol{\Delta}$ \\
\hline \multirow{2}{*}{2} & P02 & Mla3 & Ricardo (C.I. 6306) & $\boldsymbol{\Delta}$ & & & $\Delta$ & & & $\Delta$ & $\Delta$ & $\Delta$ & & & $\Delta$ & & \\
\hline & P13 & Mla23 & HOR1402 & $\boldsymbol{\Delta}$ & & & $\Delta$ & & & $\Delta$ & $\Delta$ & $\Delta$ & & & $\boldsymbol{\Delta}$ & & \\
\hline \multirow{2}{*}{3} & D*1B-86B & Mla19 & H. spontaneum 1B-86B & $\boldsymbol{\Delta}$ & & & & & & $\Delta$ & $\Delta$ & $\Delta$ & & $\Delta$ & $\Delta$ & & \\
\hline & D*1B-151 & Mla28 & H. spontaneum 1B-151 & $\boldsymbol{\Delta}$ & & & & & & $\Delta$ & $\Delta$ & $\Delta$ & & $\Delta$ & $\Delta$ & & \\
\hline \multirow{3}{*}{4} & $\mathrm{P} 01$ & Mla1 & Algerian (C.I. 1179) & & $\Delta$ & $\Delta$ & & & & $\Delta$ & $\Delta$ & $\Delta$ & & & $\Delta$ & & \\
\hline & Pallas & Mla 8 & Heils Hanna (C.I. 682) & & $\Delta$ & $\Delta$ & & & & $\Delta$ & $\Delta$ & $\Delta$ & & & $\Delta$ & & \\
\hline & $\mathrm{P} 12$ & Mla22 & HOR1657 & & $\Delta$ & $\Delta$ & & & & $\Delta$ & $\Delta$ & $\Delta$ & & & $\Delta$ & & \\
\hline \multirow{2}{*}{5} & P03 & Mla6, Mla14 & H. spontaneum 204 & & & & & & & $\Delta$ & & $\Delta$ & & & $\Delta$ & & \\
\hline & RS70-29*Picc & Mla34 & H. spontaneum $\mathrm{RS} 70-29$ & & & & & & & $\Delta$ & & $\Delta$ & & & $\Delta$ & & \\
\hline 6 & P08B & Mla9 & Monte Cristo (C.I. 1017) & & & & & $\Delta$ & & $\Delta$ & & $\Delta$ & & & $\Delta$ & & \\
\hline 7 & D*1B-20 & Mla26 & H. spontaneum $1 \mathrm{~B}-20$ & $\boldsymbol{\Delta}$ & & & & & & $\Delta$ & $\Delta$ & & & & $\Delta$ & & \\
\hline 8 & RS170-47*Kieb.B & Mla17 & H. spontaneum RS170-47 & $\boldsymbol{\Delta}$ & & & & & $\Delta$ & $\Delta$ & $\Delta$ & $\Delta$ & & & $\boldsymbol{\Delta}$ & & \\
\hline 9 & RS20-1*Kieb.B & Mla18 & H. spontaneum $\mathrm{RS} 20-1$ & $\boldsymbol{\Delta}$ & & & & & $\Delta$ & $\Delta$ & $\Delta$ & $\Delta$ & $\Delta$ & & $\Delta$ & & \\
\hline 10 & Turkey290 & Mla31 & Turkey 290 & $\boldsymbol{\Delta}$ & & & & & $\Delta$ & $\Delta$ & $\Delta$ & $\Delta$ & & $\Delta$ & $\Delta$ & $\Delta$ & \\
\hline 11 & 110-4*Sonja & Mla29 & H. spontaneum $110-4$ & $\boldsymbol{\Delta}$ & & & & & & $\boldsymbol{\Delta}$ & $\Delta$ & $\Delta$ & & $\Delta$ & $\Delta$ & & \\
\hline 12 & $\mathrm{D} * 1 \mathrm{~B}-54 \mathrm{~A}$ & Mla16 & H. spontaneum 1B-54B & $\boldsymbol{\Delta}$ & & & & & & $\Delta$ & $\Delta$ & & & $\Delta$ & $\Delta$ & & \\
\hline 13 & RS90-13*Kieb.B & Mla33 & H. spontaneum $\mathrm{RS} 90-13$ & $\boldsymbol{\Delta}$ & & & $\Delta$ & & & $\Delta$ & $\Delta$ & & & & $\Delta$ & & $\Delta$ \\
\hline
\end{tabular}




\section{DISCUSSION}

We have successfully implemented a high-throughput method to discover and detect point mutations in barley genomic DNA, using CEL I-based heteroduplex detection on an ABI PRISM $^{\text {TM }} 377$ DNA Sequencer. Most of the TILLING and EcoTILLING experiments published (Colbert et al. 2001, Wienholds et al. 2003, Smits et al. 2004, Comai et al. 2004, Slade et al. 2005) used a LI-COR detection system or an HPLC system (Caldwell et al. 2004) for the final fragment detection. We have shown that the ABI fragment detection systems is equally suitable for this purpose, as shown by Perry et al. (2003). A capillary system would be even more convenient compared to the gel-based system we used, because the large amounts of primers we used interfered with neighbouring lanes which would be less problematical in a capillary system. This would not only speed up the runs but also make automatic data analysis easier.

Selection of primers should be performed in the way that the polymorphism does not fall into the 'noisy' region 0-100 nucleotides from the primer binding site. The fluorescence primers together with the degraded PCR products, where the fluorescence dyes are attached, cause the noisy signal in the lower end of the gel. For the short 451 nucleotide fragment we could detect the mutation sites with an accuracy of \pm 1 nucleotide. The full length PCR product was always detected as a 452 nucleotide fragment. The explanation for this is probably that Taq polymerase tends to add an A to the end of PCR fragments, which makes it one nucleotide longer than the expected fragment size (Clark 1988).

We have good experience with PCR product sizes ranging from 451 to 837 base pairs. The longer the product size, the fewer primer pairs are needed to cover a large gene such as mlo. In our case we used five primer pairs to cover the entire coding region. For mlo the procedure is an efficient tool for rapid identification of genotypes as an alternative to sequencing.

For mlo, we detected DNA polymorphisms between genomes when comparing WT Mlo to each of the mlo mutants. For Mla, we detected DNA polymorphisms within the genome for each barley variant. The additional CEL I digestion products we observed in the case of Mla, indicate that one or more highly similar paralogs of the Mla sequence might exist in the barley genome. The Mla region of Hordeum vulgare ssp. vulgare cultivar 'Morex' has been sequenced (Wei et al. 2002). Although 'Morex' lacks a known Mla resistance specificity, four resistance gene paralogs $R G H 1 a, R G H 1 b c d$, RGHle and $R G H 1 f$ have been found. Also the resistance genes Mla1, Mla6 and Mla13 have been shown to have paralogs and have been named Mla1-2, Mla6-2 and Mla13-2 (Halterman and Wise 2004). We observe 5-10 point mutations in an EcoTILLING reaction with the pure line within the 451 base pair region, which corresponds to $98-99 \%$ identity. This suggests that highly identical paralogs of the gene might be present in the barley genome, either clustered with the sequenced Mla gene or at a completely different location. This hypothesis is supported by findings from classical experiments with different isolates of powdery mildew. Jørgensen (1994) found presence of 
additional genes for example in the case of 'Arabische'/'Emir' possessing Mla12 + MlEm2 genes. Perhaps this will be clarified when the barley genome is completely sequenced.

The EcoTILLING fragment patterns shown in table 4 for the Mla gene also pinpoint problems that can arise in TILLING/EcoTILLING. While single genes in homozygous diploid organisms like the mlo gene are perfectly suitable for this method, the use of TILLING in heterozygote or polyploid organisms or for genes with very similar paralogs in the same genome is more complicated. Nevertheless as shown for a polyploid organism like wheat (Slade et al. 2005) it is possible to circumvent this problem by highly specific primers. Based on our EcoTILLING results on the Mla gene supplemented by additional sequencing, specific primers can be designed and amplification of a single product might then be possible. In the case of a heterozygous organism, a prior EcoTILLING reaction with only the line itself will help to identify the two alleles present. The absolute limit of the technique will be reached if two of the factors mentioned above will coincide, for example highly similar paralogs in a heterozygous organism.

The fragment pattern we observed for the Mla gene, did not disturb our identification of the respective alleles. If the respective paralogs are clustered with the gene of interest it can be expected that the linkage between the paralogs will be very rarely broken. In the case of Mla the hypothesis of clustered paralogs is more likely than the hypothesis of distributed paralogs as we cannot distinguish some of the 'older' alleles (Jørgensen 1994). In the case of weak linkage we would expect new combinations of paralogs and thereby new fragment patterns.

We have used the fragment patterns to distinguish the varieties from each other. Out of the 25 natural barley variants, some had the same fragment pattern and grouped together (groups 1-5, table 4), whereas most of the newly identified alleles from Hordeum vulgare ssp. spontaneum had an individual pattern which will make identification possible.

Using EcoTILLING as a functional marker system has several advantages. Compared with SNP markers that detect specifically only one point mutation, EcoTILLING reveals multiple point mutations and small insertions and deletions. It could be described as Multiple Nucleotide Polymorphism (MNP) marker. Thereby a larger number of different alleles at a given locus can be studied at once. Additionally, it is not necessary to have complete knowledge of the entire sequence in several individuals. Finally, EcoTILLING also opens up further opportunities for designing SNP markers as it helps to identify polymorphic sites in organisms.

Compared to the classical determination of the disease resistance alleles present in a line through infection with specific isolates, EcoTILLING offers two main advantages: (a) there are a growing number of new alleles for powdery mildew resistance genes for the Mla locus, mainly originating from Hordeum vulgare ssp. spontaneum lines from Israel (Jahoor and Fischbeck 1993, Kintzios et al. 1995). The identification of all these new specificities is very difficult and requires the use of isolates from Israel. Since in Europe no powdery mildew population with virulence against Israeli resistance genes exists, special care has to be taken while working with those isolates to avoid an outbreak and propagation of the respective 
pathotypes. Here, EcoTILLING offers a relatively easy and appropriate alternative for identification of resistance genes with help of host-pathogen interaction. (b) When several resistance genes against one disease are combined in a line to obtain a more durable resistance (pyramiding), it is very difficult to determine the single highly effective resistance genes by isolates. In the case of a combination of the mlo-resistance with other powdery mildew resistance, particularly originating from Hordeum spontaneum genes, it is impossible to use the classical method since no virulence against mlo exists. Here, linked markers for the respective genes have been proposed. EcoTILLING markers are even more appropriate as they have the advantage of higher specificity through a higher number of possible fragment patterns and higher reliability through the lack of linkage break.

We showed that EcoTILLING is a powerful tool for the detection of SNP in the case of mlo and as a useful marker system in the case of Mla. As a marker system it combines the advantages of a functional marker, as it is based on the gene of interest itself, with a very high number of marker alleles, as every SNP on the amplified sequence results in a distinct fragment changing the overall fragment pattern.

\section{ACKNOWLEDGMENTS}

We would like to thank Lars Eriksen for helping in primer design for the Mla locus. For technical assistance, we wish to thank Hanne Hasselager. This research is supported by the Danish Ministry of Foreign Affairs and the Danish Ministry for Food, Agriculture and Fisheries. Zdenka Kyjovska received a Marie-Curie fellowship from the European Union. 


\section{REFERENCES}

Boyd, L. A., P. H. Smith, E. M. Foster, and J. K. M. Brown, 1995: The effects of allelic variation at the Mla resistance locus in barley on the early development of Erysiphe graminis f sp hordei and host responses. Plant Journal 7, 959-968.

Büschges, R., K. Hollricher, R. Panstruga, G. Simons, M. Wolter, A. Frijters, R. van Daelen, T. Van der Lee, P. Diergaarde, J. Groenendijk, S. Topsch, P. Vos, F. Salamini, and P. Schulze-Lefert, 1997: The barley mlo gene: A novel control element of plant pathogen resistance. Cell 88, 695-705.

Caldwell, D. G., N. McCallum, P. Shaw, G. J. Muehlbauer, D. F. Marshall, and R. Waugh, 2004: A structured mutant population for forward and reverse genetics in Barley (Hordeum vulgare L.). Plant Journal 40, 143-150.

Clark, J. M., 1988: Novel non-templated nucleotide addition reactions catalyzed by procaryotic and eucaryotic DNA polymerases. Nucleic Acids Research 16, 9677-9686.

Colbert, T., B. J. Till, R. Tompa, S. Reynolds, M. N. Steine, A. T. Yeung, C. M. McCallum, L. Comai, S. Henikoff, and L. Comai, 2001: High-throughput screening for induced point mutations. Plant Physiology 126, 480-484.

Comai, L., K. J. Young, C. A. Codomo, L. C. Enns, J. E. Johnson, C. Burtner, A. R. Odden, S. Henikoff, S. H. Reynolds, and E. A. Greene, 2004: Efficient discovery of DNA polymorphisms in natural populations by Ecotilling. Plant Journal 37, 778-786.

Halterman, D. A., and R. P. Wise, 2004: A single-amino acid substitution in the sixth leucinerich repeat of barley MLA6 and MLA13 alleviates dependence on RAR1 for disease resistance signaling. Plant Journal 38, 215-226.

Jahoor, A., and G. Fischbeck, 1987: Genetic studies of resistance to powdery mildew in barley lines derived from Hordeum spontaneum collected from Israel. Plant Breeding 99, 265273.

Jahoor, A., and G. Fischbeck, 1993: Identification of new genes for mildew resistance of barley at the Mla locus in lines derived from Hordeum spontaneum. Plant Breeding 110, 116122.

Jørgensen, J. H., 1994: Genetics of powdery mildew resistance in barley. Critical Reviews in Plant Sciences 13, 97-119.

Kintzios, S., A. Jahoor, and G. Fischbeck, 1995: Powdery mildew resistance genes Mla29 and Mla32 in H. spontaneum derived winter barley lines. Plant Breeding 114, 265-266.

Kølster, P., L. Munk, O. Støllen, and J. Lohde, 1986: Near-isogenic barley lines with genes for resistance to powdery mildew. Crop Science 26, 903-907.

McCallum, C. M., L. Comai, E. A. Greene, and S. Henikoff, 2000: Targeting induced local lesions in genomes (TILLING) for plant functional genomics. Plant Physiology 123, 439-442. 
Molina-Cano, J. L., J. P. Simiand, A. Sopena, A. M. Pérez-Vendrell, S. Dorsch, D. Rubiales, J. S. Swanston, and A. Jahoor, 2003: Mildew-resistant mutants induced in North American two- and six-rowed malting barley cultivars. Theoretical and Applied Genetics 107, 12781287.

Oleykowski, C. A., C. R. B. Mullins, A. K. Godwin, and A. T. Yeung, 1998: Mutation detection using a novel plant endonuclease. Nucleic Acids Research 26, 4597-4602.

Perry, J. A., T. L. Wang, T. J. Welham, S. Gardner, J. M. Pike, S. Yoshida, and M. Parniske, 2003: A TILLING reverse genetics tool and web-accessible collection of mutants of the legume Lotus japanicus. Plant Physiology 131, 866-871.

Piffanelli, P., L. Ramsay, R. Waugh, A. Benabdelmouna, A. D'Hont, K. Hollricher, J. H. Jørgensen, P. Schulze-Lefert, and R. Panstruga, 2004: A barley cultivation-associated polymorphism conveys resistance to powdery mildew. Nature 430, 887-891.

Piffanelli, P., F. Zhou, C. Casais, J. Orme, B. Jarosch, U. Schaffrath, N. C. Collins, R. Panstruga, and P. Schulze-Lefert, 2002: The barley MLO modulator of defense and cell death is responsive to biotic and abiotic stress stimuli. Plant Physiology 129, 1076-1085.

Rozen, S., and H. J. Skaletsky, 1988: Primer3 on the WWW for general users and for biologist programmers. In: S. Krawetz and S. Misener (eds.), Bioinformatics Methods and Protocols: Methods in Molecular Biology, 365-386. Humana Press, Totowa, NJ.

Saghai-Maroof, M. A., K. M. Soliman, R. A. Jørgensen, and R. W. Allard, 1984: Ribosomal DNA spacer-length polymorphisms in barley: Mendelian inheritance, chromosomal location, and population-dynamics. Proceedings of the National Academy of Sciences 81, 8014-8018.

Slade, A. J., S. Fuerstenberg, D. Loeffler, M. N. Steine, and D. Facciotti, 2005: A reverse genetic, nontransgenic approach to wheat crop improvement by TILLING. Nature Biotechnology 23, 75-81.

Smits, B. M. G., U. M. D'Souza, E. Berezikov, E. Cuppen, and F. Sluyter, 2004: Identifying polymorphisms in the Rattus norvegicus $\mathrm{D}_{3}$ dopamine receptor gene and regulatory region. Genes, Brain and Behavior 3, 138-148.

Wei, F., R. A. Wing, and R. P. Wise, 2002: Genome dynamics and evolution of the Mla (powdery mildew) resistance locus in barley. The Plant Cell 14, 1903-1917.

Wienholds, E., F. van Eeden, M. Kosters, J. Mudde, R. H. A. Plasterk, and E. Cuppen, 2003: Efficient target-selected mutagenesis in zebrafish. Genome Research 13, 2700-2707.

Yang, B., X. Wen, N. S. Kodali, C. A. Oleykowski, C. G. Miller, J. Kulinski, D. Besack, J. A. Yeuhg, D. Kowalski, and A. T. Yeung, 2000: Purification, cloning, and characterization of the CEL I nuclease. Biochemistry 39, 3533-3541. 